Photochemical \& Photobiological Sciences

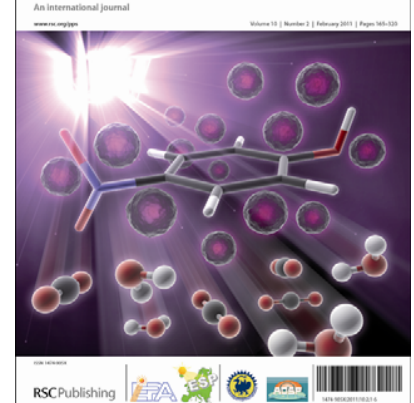

This article is published as part of a themed issue of Photochemical \& Photobiological Sciences of contributions from:

6th European Meeting on Solar Chemistry and Photocatalysis: Environmental Applications

Guest edited by Josef Krysa and Sixto Malato

Published in issue 3, 2011

Papers

Performance of the photo-Fenton process in the degradation of a model azo dye mixture J. Macías-Sánchez et al., Photochem. Photobiol. Sci., 2011, 10, 332, DOI: 10.1039/C0PP00158A

Principles and test methods for the determination of the activity of photocatalytic materials and their application to modified building materials

K. Amrhein and D. Stephan, Photochem. Photobiol. Sci., 2011, 10, 338, DOI: 10.1039/C0PP00155D

Photocatalytic activity of S- and F-doped $\mathrm{TiO}_{2}$ in formic acid mineralization

M. V. Dozzi et al.i, Photochem. Photobiol. Sci., 2011, 10, 343, DOI: 10.1039/C0PP00182A

Visible light induced wetting of nanostructured N-F co-doped titania films

A. G. Kontos et al., Photochem. Photobiol. Sci., 2011, 10, 350, DOI: 10.1039/COPP00159G

Effect of titanium dioxide crystalline structure on the photocatalytic production of hydrogen

G. L. Chiarello et al., Photochem. Photobiol. Sci., 2011, 10, 355, DOI: 10.1039/C0PP00154F

Photocatalytic activity of nano and microcrystalline $\mathrm{TiO}_{2}$ hybrid systems involving phthalocyanine or porphyrin sensitizers

R. Słota et al., Photochem. Photobiol. Sci., 2011, 10, 361, DOI: 10.1039/COPP00160K

Degradation of dichloroacetic acid in homogeneous aqueous media employing ozone and UVC radiation

M. E. Lovato et al., Photochem. Photobiol. Sci., 2011, 10, 367, DOI: 10.1039/COPP00208A

Solar disinfection of fungal spores in water aided by low concentrations of hydrogen peroxide M. I. Polo-López et al., Photochem. Photobiol. Sci., 2011, 10, 381, DOI: 10.1039/C0PP00174K

Disinfection of water and wastewater by UV-A and UV-C irradiation: application of real-time PCR method

E. Chatzisymeon et al., Photochem. Photobiol. Sci., 2011, 10, 389, DOI: 10.1039/C0PP00161A

Modeling partial oxidation of a commercial textile surfactant formulation with the $\mathrm{H}_{2} \mathrm{O}_{2} / \mathrm{UV}-\mathrm{C}$ process I. Arslan-Alaton et al., Photochem. Photobiol. Sci., 2011, 10, 396, DOI: 10.1039/C0PP00170H

Microstructure and performance of titanium oxide coatings sprayed by oxygen-acetylene flame P. Ctibor et al., Photochem. Photobiol. Sci., 2011, 10, 403, DOI: 10.1039/C0PP00166J

Application of the UV-C photo-assisted peroxymonosulfate oxidation for the mineralization of dimethyl phthalate in aqueous solutions

T. Olmez-Hanci et al., Photochem. Photobiol. Sci., 2011, 10, 408, DOI: 10.1039/C0PP00173B

Intensification of gas-phase photoxidative dehydrogenation of ethanol to acetaldehyde by using phosphors as light carriers

P. Ciambelli et al., Photochem. Photobiol. Sci., 2011, 10, 414, DOI: 10.1039/COPP00186D

Mesoporous films of $\mathrm{TiO}_{2}$ as efficient photocatalysts for the purification of water J. Rathouský et al., Photochem. Photobiol. Sci., 2011, 10, 419, DOI: 10.1039/C0PP00185F

Intermediates in photochemistry of Fe(III) complexes with carboxylic acids in aqueous solutions E. M. Glebov et al., Photochem. Photobiol. Sci., 2011, 10, 425, DOI: 10.1039/C0PP00151A

A photoactivated fuel cell used as an apparatus that consumes organic wastes to produce electricity M. Antoniadou and P. Lianos, Photochem. Photobiol. Sci., 2011, 10, 431, DOI: 10.1039/C0PP00148A 


\title{
Effect of titanium dioxide crystalline structure on the photocatalytic production of hydrogen $\uparrow$
}

\author{
Gian Luca Chiarello, ${ }^{a}$ Agatino Di Paola, ${ }^{b}$ Leonardo Palmisano ${ }^{b}$ and Elena Selli*a
}

\author{
Received 11th June 2010, Accepted 6th August 2010 \\ DOI: $10.1039 / \mathrm{copp00154f}$
}

\begin{abstract}
The effect of the crystalline phase of $\mathrm{TiO}_{2}$ (anatase, rutile and brookite) on its photocatalytic activity in hydrogen production from methanol-water vapours has been investigated by testing a series of both home-made and commercial $\mathrm{TiO}_{2}$ photocatalysts, either bare or surface-modified by deposition of a fixed amount, i.e. $1 \mathrm{wt} \%$, of platinum as co-catalyst. For all of the $\mathrm{TiO}_{2}$ samples the rate of hydrogen production increased by one order of magnitude upon Pt deposition, because of the ability of Pt to enhance the separation of photoproduced electron-hole pairs. Under irradiation in the $350-450 \mathrm{~nm}$ wavelength range, brookite and anatase showed similar photoactivities, both superior to that of rutile. By contrast, rutile, possessing a narrower band gap, was active also under visible light $(\lambda>400 \mathrm{~nm})$, whereas no hydrogen evolution was observed with anatase and brookite under such conditions. Surface area proved to be a key parameter, strongly influencing photoactivity. However, as the particle size became ultra-small, the semiconductor absorption edge was blue-shifted because of size quantisation effects, with a consequent decrease in hydrogen production rate due to the smaller portion of incident photons absorbed by the photocatalyst.
\end{abstract}

\section{Introduction}

Titanium dioxide, the most widely studied photocatalyst in consideration of its high activity, chemical inertness, low cost and non-toxicity, ${ }^{1}$ mainly exists in the three different crystalline forms: rutile, anatase and brookite. All of them consist of deformed $\mathrm{TiO}_{6}$ octahedra connected differently by corners and edges. ${ }^{2}$ At room temperature rutile is more stable than anatase and brookite, but anatase becomes the thermodynamically most stable polymorph when the particle size decreases below $15 \mathrm{~nm}^{3}$

$\mathrm{TiO}_{2}$ is generally prepared by thermolysis, hydrothermal synthesis and sol-gel processes. Titania nanotubes can be prepared by electrochemical anodization. ${ }^{4,5}$ Anatase and rutile are the forms more frequently studied because pure brookite is quite difficult to synthesise. Brookite has been prevalently prepared from titanium(IV) compounds via hydrothermal treatments at high temperature, ${ }^{6-8}$ but recently brookite nanoparticles have been synthesised under mild temperature and pressure conditions, ${ }^{9-11}$ also by employing titanium(III) compounds as $\mathrm{TiO}_{2}$ precursors. ${ }^{12}$

Anatase is generally considered the most efficient $\mathrm{TiO}_{2}$ polymorph in photocatalytic reactions, whereas the activity of the rutile phase can be strongly affected by the preparation conditions. ${ }^{13}$ Only a very limited number of studies examined the photocatalytic behaviour of brookite so far. For example, brookite revealed good photocatalytic capacity for the photodegradation of 4-nitrophenol ${ }^{11}$ and 4-chlorophenol. ${ }^{12}$ Thin films of brookite

${ }^{a}$ Dipartimento di Chimica Fisica ed Elettrochimica, CIMaINa and ISTMCNR, Università degli Studi di Milano, via Golgi 19, I-20133, Milano, Italy. E-mail: elena.selli@unimi.it; Fax: +3902503 14300; Tel: +390250314237 ${ }^{b}$ Schiavello-Grillone Photocatalysis Group, Dipartimento di Ingegneria Chimica dei Processi e dei Materiali, Università di Palermo, viale delle Scienze, 90128, Palermo, Italy

$\dagger$ This paper is published as part of the themed issue of contributions from the 6th European Meeting on Solar Chemistry and Photocatalysis: Environmental Applications held in Prague, Czech Republic, June 2010. showed a good efficiency for the gas-phase photo-oxidation of 2-propanol, ${ }^{14,15}$ and brookite powders were employed for the selective photocatalytic oxidation of an aromatic alcohol to aldehyde in an organic-free water suspension. ${ }^{16}$ Recently, brookite has been also successfully employed in the photocatalytic production of hydrogen. ${ }^{17-20}$ Generally, anatase/brookite mixtures and pure brookite were found to be more photoactive than pure anatase or rutile. Thus, the photocatalytic performance of brookite deserves a more in depth investigation.

The photocatalytic activity in hydrogen production, either from direct water splitting or from reforming of organics, ${ }^{21-23}$ these latter acting as sacrificial agents able to combine with photo-produced holes more efficiently than water itself, has been recently investigated by some of us, employing methanol as sacrificial agent and a series of differently prepared rutile- and/or anatase-containing photocatalysts, also modified by addition of noble metal nanoparticles. ${ }^{23-25}$ A remarkable increase in the reaction rate was attained by feeding the photocatalyst with methanol-water vapours instead of working in liquid suspension, due to the elimination of mass transfer effects in hydrogen evolution. ${ }^{25}$

In the present work the effect of the crystal structure of $\mathrm{TiO}_{2}$ has been systematically investigated in relation to its photoactivity in hydrogen production from methanol photo-steam reforming. In particular, besides home-made and commercial anatase samples, a home-made rutile and a pure brookite sample have been tested as photocatalysts in this reaction, together with a series of rutile samples with different particles size and surface area, in order to get information on the effects of such structural features on the photocatalytic performance. Different cut-off filters were also employed to ascertain the visible light photoactivity of the investigated samples. The results have been interpreted mainly on the basis of band gap energies and of conduction flat-band potentials. 


\section{Experimental}

\subsection{Photocatalyst preparation}

Anatase (A), brookite (B) and rutile (R) titanium dioxide were synthesised by thermo-hydrolysis, starting from titanium tetrachloride as precursor. ${ }^{26}$ Anatase was prepared by boiling an aqueous solution of $\mathrm{TiCl}_{4}\left(\mathrm{TiCl}_{4}: \mathrm{H}_{2} \mathrm{O}\right.$ volume ratio $\left.1: 50\right)$ for $2 \mathrm{~h}$. After removal of the supernatant liquid, the solid was dried under vacuum at $55^{\circ} \mathrm{C}$. Brookite and rutile were obtained by adding $\mathrm{TiCl}_{4}$ dropwise to an aqueous $\mathrm{HCl}$ solution at room temperature and the obtained solution was heated in a closed bottle and aged at $100{ }^{\circ} \mathrm{C}$ also in oven for $48 \mathrm{~h}$. The resultant precipitate contained a mixture of brookite and rutile. Pure brookite was separated by peptisation, through several cycles of surnatant removal followed by water addition up to the initial volume. When the $\mathrm{pH}$ was higher than 0.8 , a dispersion of brookite particles formed, whereas the rutile phase remained as precipitate. The sol containing the brookite particles and the rutile precipitate were separately dried under vacuum at $55^{\circ} \mathrm{C}$.

Commercial pure anatase (A-C) and rutile (R1-C and R2-C) $\mathrm{TiO}_{2}$ purchased from Sigma-Aldrich were also investigated as received, for comparison.

Preformed platinum nanoparticles stabilized by n-dodecyl trimethylammonium chloride were deposited on all the above mentioned $\mathrm{TiO}_{2}$ samples by means of the already described reverse micelles method, ${ }^{24}$ using aliquots of the same Pt colloidal suspension. Briefly, the proper amount of the Pt precursor (chloroplatinic acid) was dissolved in an aqueous solution containing the surfactant (40:1 surfactant to $\mathrm{Pt}$ molar ratio). Pt colloidal suspensions were then obtained by adding $\mathrm{NaBH}_{4}$ aqueous solution (4:1 $\mathrm{NaBH}_{4}$ to Pt molar ratio) under vigorous stirring. An aliquot of the colloidal suspension was added to the required amount of $\mathrm{TiO}_{2}$ powder pre-dispersed in water, under vigorous stirring. Finally, the obtained powder was recovered, washed and dried in an oven at $70{ }^{\circ} \mathrm{C}$. The advantages of this deposition method are: $(i)$ ensuring the same Pt particles size distribution for all of the photocatalysts; (ii) avoiding any structure modification of the $\mathrm{TiO}_{2}$ support, because Pt deposition is carried out in water at room temperature. Well-dispersed Pt particles, ca. 5-6 nm in size, are obtained by the here adopted deposition procedure. ${ }^{24}$

\subsection{Photocatalyst characterisation}

BET specific surface area was measured by $\mathrm{N}_{2}$ adsorption/desorption at $77 \mathrm{~K}$ in a Micromeritics ASAP 2010 apparatus, after out-gassing in vacuo at $300{ }^{\circ} \mathrm{C}$ for at least $6 \mathrm{~h}$.

$\mathrm{X}$-Ray diffraction (XRD) patterns were recorded on a Philips PW3020 powder diffractometer, by using the $\mathrm{Cu}-\mathrm{K} \alpha$ radiation $(\lambda=$ $1.54056 \AA$ ). Quantitative phase analysis was made by the Rietveld refinement method, ${ }^{27}$ using the "Quanto" software. ${ }^{28}$

UV-Vis diffuse reflectance (DR) spectra were recorded by a Perkin-Elmer Lambda 35 apparatus equipped with an integration sphere (Labsphere RSA-PE-20).

Scanning electron microscopy (SEM) analysis was carried out on a LEICA LEO 1430 instrument.

\subsection{Photocatalytic tests}

The peculiar structural features of the investigated photocatalyst in hydrogen production from methanol photo-steam reforming:

$$
\mathrm{CH}_{3} \mathrm{OH}+\mathrm{H}_{2} \mathrm{O} \stackrel{h v, \mathrm{TiO}_{2}}{\longrightarrow} \mathrm{CO}_{2}+3 \mathrm{H}_{2}
$$

was tested in the expressly set up, closed recirculation laboratory scale apparatus sketched in Fig. 1, similar to that employed in previous studies. ${ }^{24,25}$

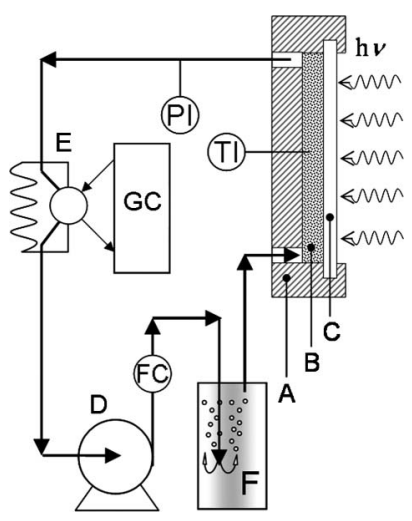

Fig. 1 Sketch of the experimental setup for photocatalytic activity tests: (A) cross section of the Plexiglas photoreactor; (B) photocatalyst bed; (C) Pyrex glass window; (GC) gas chromatograph; (E) six ways sampling valve; (D) bellow pump; (F) thermostatted bubbler; (FC) gas flow meter; (TI) temperature indicator; (PI) pressure indicator.

The photocatalyst powder was deposited on 20-40 mesh (0.85$0.42 \mathrm{~mm}$ ) quartz beads by mixing $14 \mathrm{mg}$ of it with $3 \mathrm{~g}$ of quartz beads and $1.2 \mathrm{~mL}$ of distilled water, followed by drying in oven at $70{ }^{\circ} \mathrm{C}$ for $6 \mathrm{~h}$. The so-obtained photocatalyst bed was inserted in the photoreactor consisting in a flat cylindrical Plexiglas cell, having a central $2 \mathrm{~mm}$ thick and $50 \mathrm{~mm}$ in diameter round hollow, frontally closed by a Pyrex glass optical window (irradiation surface $c a .20 \mathrm{~cm}^{2}$ ). The photoreactor was connected to a closed stainless steel system (see Fig. 1), where the gas phase was recirculated at a constant rate by means of a metal bellow pump. The system was preliminarily purged with nitrogen in order to remove any oxygen trace. During the photocatalytic tests, the photocatalyst bed was continuously fed with a stream of $40 \mathrm{~mL} \mathrm{~min} \mathrm{~m}^{-1}$ of $\mathrm{N}_{2}$ saturated with the vapour of a $20 \mathrm{vol} \%$ methanol-water solution thermostatted at $30^{\circ} \mathrm{C}$, corresponding to a methanol molar fraction $x$ of 0.10 in the liquid phase. The reactor temperature during irradiation was $55 \pm 5{ }^{\circ} \mathrm{C}$, as monitored by a thermocouple placed inside the cell. The absolute pressure was 1.2 bar at the beginning of the runs and slightly increased during irradiation, as a consequence of the accumulation of products in the gas phase. During the runs, typically lasting $6 \mathrm{~h}$, the recirculating gas was analysed on-line by sampling it every 20 min by means of a pneumatic sampling valve placed at the exit of the photoreactor. Gas samples were automatically injected into an Agilent $6890 \mathrm{~N}$ gas-chromatograph, equipped with two columns (HP-PlotU and Molesive 5A), two detectors (thermoconductivity and flame ionisation) and a Ni-catalyst kit for $\mathrm{CO}$ and $\mathrm{CO}_{2}$ methanation. $\mathrm{N}_{2}$ was used as carrier gas. The GC response was calibrated by injecting known volumes of $\mathrm{H}_{2}$, $\mathrm{CO}$ and $\mathrm{CO}_{2}$ into the recirculation system through the loop of a six ways sampling valve. When testing Pt-modified photocatalysts, purging by nitrogen in the dark was required every $2 \mathrm{~h}$, due to the high products accumulation in the recirculating gas phase. 
Table 1 BET surface area (SA), phase composition and average crystallite diameter $D_{\text {XRD }}$, from XRD analysis, and band gap energy $\left(E_{\mathrm{g}}\right)$ from DR spectra of the investigated $\mathrm{TiO}_{2}$ photocatalysts

\begin{tabular}{lllllll}
\hline Sample & $\mathrm{SA} / \mathrm{m}^{2} \mathrm{~g}^{-1}$ & $\begin{array}{l}\text { Anatase } \\
(\mathrm{wt} \%)\end{array}$ & $\begin{array}{l}\text { Rutile } \\
(\mathrm{wt} \%)\end{array}$ & $\begin{array}{l}\text { Brookite } \\
(\mathrm{wt} \%)\end{array}$ & $D_{\text {XRD }} / \mathrm{nm}$ & $E_{\mathrm{g}} / \mathrm{eV}$ \\
\hline $\mathrm{A}^{a}$ & 180 & 82 & - & 18 & 3.5 & 3.00 \\
$\mathrm{~B}^{a}$ & 80 & - & - & 100 & 8.1 & 3.10 \\
$\mathrm{R}^{a}$ & 25 & - & 88 & 12 & 5.6 & 2.95 \\
$\mathrm{~A}^{-} \mathrm{C}^{b}$ & 142 & 100 & - & - & 9.4 & 3.15 \\
$\mathrm{R}^{-}-\mathrm{C}^{b}$ & 139 & - & 100 & - & 3.5 & 3.05 \\
$\mathrm{R}^{2}-\mathrm{C}^{b}$ & 2.2 & 5 & 95 & - & 58.9 & 2.95
\end{tabular}

${ }^{a}$ Synthesised by thermo-hydrolysis. ${ }^{b}$ Commercial sample.

The irradiation source was an iron halogenide mercury arc lamp (Jelosil, $250 \mathrm{~W}$ ), placed at $20 \mathrm{~cm}$ from the reactor, emitting in the $350-450 \mathrm{~nm}$ wavelength range with a full irradiation intensity of $1.67 \times 10^{-7}$ einstein $\mathrm{s}^{-1} \mathrm{~cm}^{-2}$ on the reactor, determined by ferrioxalate actinometry. ${ }^{29}$ Its constancy was checked daily by means of a UVA lux-metre.

\section{Results and discussion}

\subsection{Photocatalysts characterisation}

The structural features of the investigated $\mathrm{TiO}_{2}$ photocatalysts are summarised in Table 1. The results of XRD analysis, reported in Fig. 2, evidence that the home-made B sample consisted of pure brookite, whereas the two other home-made A and R samples mainly consisted of anatase and rutile, respectively, but also contained a significant amount of brookite. Commercial $\mathrm{TiO}_{2}$ samples consisted of pure phases, apart from low surface area R2-C rutile, which also contained a non-negligible amount of anatase. As expected, we found that both the BET surface area and the crystalline phase composition did not significantly change upon Pt deposition by the here adopted procedure.

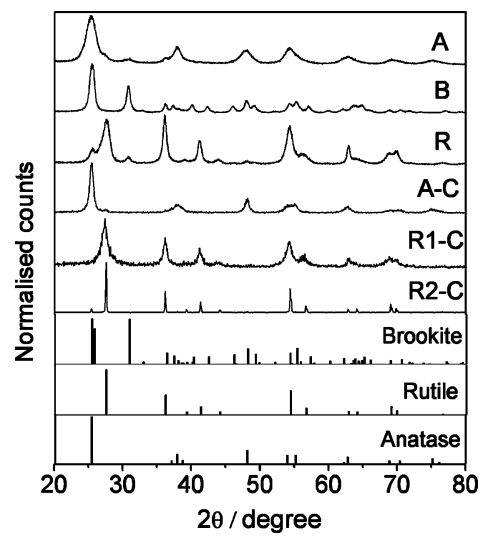

Fig. 2 XRD patterns of the investigated bare $\mathrm{TiO}_{2}$ samples and position of the diffraction peaks of the $\mathrm{TiO}_{2}$ crystalline phases.

The average crystallite diameter $D_{\text {XRD }}$ values reported in Table 1 were calculated, by applying the Scherrer equation, from the integral XRD peak width calculated as the ratio between peak area and peak intensity obtained by fitting with a Gaussian function the profile of the most intense reflections at $2 \theta=25.4^{\circ}$ for anatase, $27.5^{\circ}$ for rutile and $30.7^{\circ}$ for brookite.
The UV-Vis absorption spectra of pure and Pt-deposited $\mathrm{TiO}_{2}$ samples are shown in Fig. 3. Bulk rutile notoriously has a narrower band gap than anatase and brookite. Indeed, samples R and R2-C exhibit an absorption onset threshold located at $c a .420 \mathrm{~nm}$, i.e. red-shifted with respect to those of $\mathrm{A}, \mathrm{A}-\mathrm{C}$ and $\mathrm{B}$, which are located below $400 \mathrm{~nm}$ (Fig. 3a). By contrast, the absorption edge of R1-C is blue-shifted with respect to that of the other rutile samples. This can reasonably be attributed to the so-called "size quantisation effect" observed with ultra-small semiconductor particles, ${ }^{30}$ which is known to lead to a widening of the band gap. In fact, R1-C possesses a surface area much larger than those of the $\mathrm{R}$ and R2-C rutile samples (139 vs. 25 and $2.2 \mathrm{~m}^{2} \mathrm{~g}^{-1}$, respectively) and consequently it is expectedly constituted of smaller size particles, as confirmed by the average crystallite diameter $D_{\text {XRD }}$ (Table 1) and also by the SEM micrographs reported in Fig. 4. Indeed, this figure shows that sample R1-C, as well as samples A, A-C and B, essentially consist of agglomerates of nanoparticles. On the other

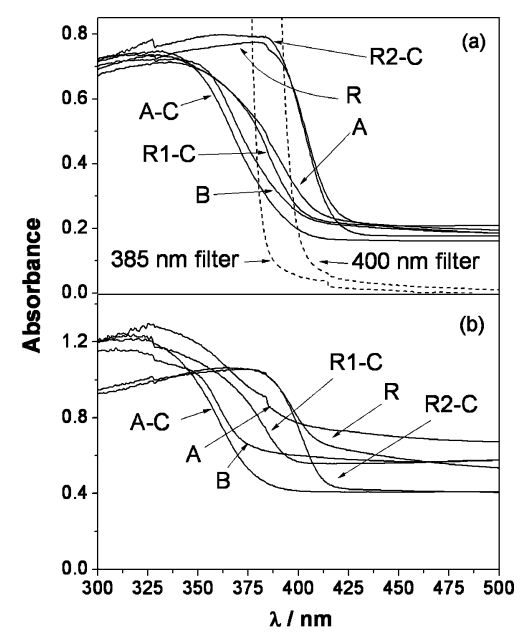

Fig. 3 UV-Vis absorption spectra of (a) unmodified $\mathrm{TiO}_{2}$ samples labelled as in Table 1 (continuous lines) and of the employed $385 \mathrm{~nm}$ and $400 \mathrm{~nm}$ band pass filters (dashed lines); (b) the same $\mathrm{TiO}_{2}$ samples modified by $1 \mathrm{wt} \% \mathrm{Pt}$ deposition.

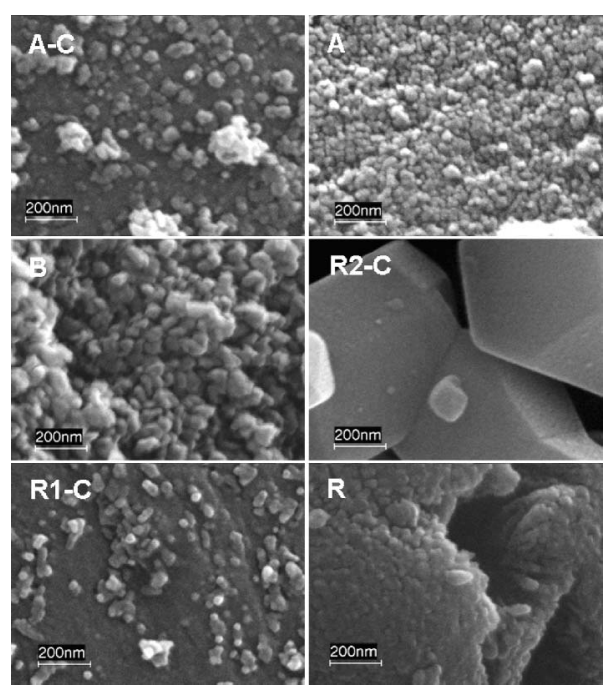

Fig. 4 SEM micrographs of the investigated bare $\mathrm{TiO}_{2}$ samples. 
hand, sample R2-C is formed by much larger crystallites, whereas sample $\mathrm{R}$ exhibits a sort of sponge-like morphology.

As shown in Fig. 3b, the grey Pt-containing $\mathrm{TiO}_{2}$ powders exhibit broad and structureless absorption in the visible region due to the plasmon resonance of the noble metal nanoparticles on the $\mathrm{TiO}_{2}$ surface, together with the onset of semiconductor band gap absorption located at the same wavelength of the corresponding unmodified $\mathrm{TiO}_{2}$ samples (see Fig. 3a).

\subsection{Photocatalytic tests}

A recent, systematic investigation on the photocatalytic steam reforming reaction of methanol evidenced that methanol undergoes oxidation up to $\mathrm{CO}_{2}$ through the formation of formaldehyde and formic acid as intermediate species; carbon monoxide, methane, methyl formate, dimethyl ether and acetaldehyde were also identified as side products. ${ }^{24}$

The products distribution and their selectivity can be tuned by changing the methanol molar fraction $x$ in the liquid solution, thus changing the ratio of the methanol to water partial pressure in the feeding mixture. In particular, $\mathrm{H}_{2}$ and $\mathrm{CO}_{2}$ evolution close to the molar ratio expected from overall methanol steam reforming (reaction (1)) is achieved only for very low $x$ values $(x<0.01)$ and formaldehyde becomes the main product detected in the gas phase, for higher $x$ values. Furthermore, the rate of hydrogen production $r_{\mathrm{H}_{2}}$ follows a bell-shaped curve when plotted vs. $x$, with a maximum at $x=0.4$, and the rate of $\mathrm{CO}_{2}$ production $r_{\mathrm{CO}_{2}}$ exhibits a hyperbolic decay curve $v$ s. $x$. Hence, we adopted $x=$ 0.1 as standard reaction condition in the present study, because it represents a good compromise between a high $r_{\mathrm{H}_{2}}$ value and high selectivity in hydrogen production to $\mathrm{CO}_{2}, S_{\mathrm{CO}_{2}}$, defined as $S_{\mathrm{CO}_{2}}=\left(3 r_{\mathrm{CO}_{2}} / r_{\mathrm{H}_{2}}\right) \times 100$. The selectivity to $\mathrm{CO}$ is defined as $S_{\mathrm{CO}}=$ $\left(2 r_{\mathrm{CO}} / r_{\mathrm{H}_{2}}\right) \times 100$.

In all photocatalytic tests $\mathrm{H}_{2}, \mathrm{CO}_{2}$ and $\mathrm{CO}$ evolution occurred at constant rate during irradiation, as in previous studies. ${ }^{24}$ The rates of $\mathrm{H}_{2}, \mathrm{CO}_{2}$ and $\mathrm{CO}$ production obtained with the investigated photocatalysts are reported in Table 2, together with the $S_{\mathrm{CO}_{2}}$ and $S_{\mathrm{CO}}$ selectivity values. It is worth recalling that the rate of $\mathrm{CO}$ production is very important when considering photocatalytic

Table 2 Rates of $\mathrm{H}_{2}, \mathrm{CO}_{2}$ and $\mathrm{CO}$ production $(r)$ and percent selectivity to $\mathrm{CO}_{2}$ and $\mathrm{CO}$ in hydrogen production on bare and on $1 \mathrm{wt} \% \mathrm{Pt}$-modified $\mathrm{TiO}_{2}$ photocatalysts

\begin{tabular}{|c|c|c|c|c|c|}
\hline \multirow[b]{2}{*}{ Sample } & \multicolumn{3}{|c|}{$r / \mathrm{mmol} \mathrm{h}^{-1} \mathrm{~g}_{\mathrm{cat}}{ }^{-1}$} & \multicolumn{2}{|c|}{$\%$ Selectivity } \\
\hline & $\mathrm{H}_{2}$ & $\mathrm{CO}_{2}$ & $\mathrm{CO}$ & $\mathrm{CO}_{2}$ & $\mathrm{CO}$ \\
\hline $\mathrm{A}^{a}$ & 1.14 & 0.098 & 0.034 & 26 & 6.0 \\
\hline$A-C^{b}$ & 0.97 & 0.044 & 0.040 & 14 & 8.2 \\
\hline $\mathrm{B}^{a}$ & 0.95 & 0.070 & 0.017 & 22 & 3.6 \\
\hline $\mathrm{R}^{a}$ & 0.55 & 0.110 & 0.026 & 60 & 9.5 \\
\hline $\mathrm{R} 1-\mathrm{C}^{b}$ & 0.27 & 0.033 & 0.009 & 37 & 6.7 \\
\hline $\mathrm{R} 2-\mathrm{C}^{b}$ & 0.05 & 0.015 & 0.001 & 90 & 5.6 \\
\hline $\mathrm{Pt} / \mathrm{A}$ & 12.8 & 1.20 & 0.041 & 28 & 0.6 \\
\hline $\mathrm{Pt} / \mathrm{A}-\mathrm{C}$ & 11.7 & 1.01 & 0.150 & 26 & 2.6 \\
\hline $\mathrm{Pt} / \mathrm{B}$ & 13 & 1.83 & 0.076 & 42 & 1.2 \\
\hline $\mathrm{Pt} / \mathrm{R}$ & 5.7 & 0.81 & 0.030 & 43 & 1.1 \\
\hline $\mathrm{Pt} / \mathrm{R} 1-\mathrm{C}$ & 3.44 & 0.27 & 0.028 & 24 & 1.6 \\
\hline $\mathrm{Pt} / \mathrm{R} 2-\mathrm{C}$ & 0.66 & 0.036 & 0.004 & 16 & 1.3 \\
\hline
\end{tabular}

${ }^{a}$ Synthesised by thermo-hydrolysis. ${ }^{b}$ Commercial sample. hydrogen as a feedstock for fuel cells. In fact, $\mathrm{CO}$ would certainly be the most undesired by-product, being a well-known poison for Pt-based catalysts in fuel cells.

Among the unmodified oxides, anatase (A and A-C samples) confirmed to be the most photoactive photocatalysts under UVVis irradiation (Table 2 and Fig. 5). However, brookite showed an activity in hydrogen production almost comparable to that of anatase, whereas rutile was the less photoactive $\mathrm{TiO}_{2}$ polymorph, though displaying the desired highest selectivity to $\mathrm{CO}_{2}, S_{\mathrm{CO}_{2}}$.

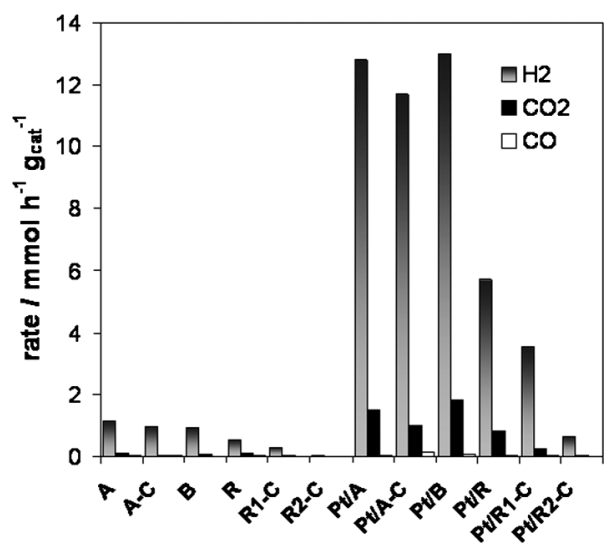

Fig. 5 Comparison of the rates of $\mathrm{H}_{2}, \mathrm{CO}_{2}$ and $\mathrm{CO}$ production $(r)$ on bare and on $1 \mathrm{wt} \%$ Pt-deposited $\mathrm{TiO}_{2}$ samples under UV-Vis irradiation $(350<\lambda<450 \mathrm{~nm})$.

On Pt-deposited $\mathrm{TiO}_{2}$ samples the rate of hydrogen production was systematically more than ten-fold higher in comparison to the values obtained with the corresponding bare oxides. Indeed, noble metal nanoparticles on the semiconductor surface are able to capture photopromoted conduction band electrons, due to the electronic potential barrier generated by the band alignment at the metal/semiconductor heterojunction (Schottky barrier). This phenomenon favours interface electron transfer, thus increasing the efficiency of charge separation of the electron-hole pairs photo-generated on the semiconductor upon light absorption. In this case methanol photo-oxidation occurs at the semiconductor surface, acting as photo-anode, whereas hydrogen evolution takes place on the Pt surface, acting as photo-cathode.

Upon $1 \mathrm{wt} \% \mathrm{Pt}$ deposition on $\mathrm{TiO}_{2}$, also the rates of $\mathrm{CO}_{2}$ production increased, though by different extents for the different types of photocatalysts, and at the same time the selectivity to carbon monoxide significantly decreased, for all of the investigated photocatalysts (Table 2). Pt-modified brookite was even slightly more active than anatase, in terms of both $r_{\mathrm{H}_{2}}$ and $r_{\mathrm{CO}_{2}}$ values, and rutile remained the less photoactive polymorph. This trend can be in part explained by taking into account the potential values of the conduction band edges $\left(E_{\mathrm{CB}}\right)$ of the three polymorphs. According to a previous work, ${ }^{26}$ anatase and brookite have similar $E_{\mathrm{CB}}$ values, i.e. -0.45 and $-0.46 \mathrm{~V} v s$. NHE at $\mathrm{pH} 7$, respectively. It is worth noting that more cathodic $E_{\mathrm{CB}}$ values, i.e. $-0.51 \mathrm{~V}$ for anatase nanoparticles and $-0.65 \mathrm{~V}$ for brookite nanorods were recently reported.$^{18}$ The difference among these values might be attributed to differences in the nature of the materials (powders, nanorods, films) or to the different methods of estimating $E_{\mathrm{CB}}$. A less negative $E_{\mathrm{CB}}$ value, i.e. $-0.37 \mathrm{~V} v$ s. $\mathrm{NHE}$ at $\mathrm{pH} 7$, has been estimated for rutile. ${ }^{26}$ 
Hence, the electrons photopromoted in anatase and brookite conduction bands have a similar potential suitable to promote hydrogen formation, which is greater with respect to that of rutile. However, possibly due to the presence of brookite, the flat band potential of the $\mathrm{R}$ sample is sufficiently negative to allow hydrogen evolution in the vapour phase.

Of course, not only bulk properties should be invoked to account for the results reported in Table 2, but also the different surface adsorption properties and reactivity must be considered. Several infrared spectroscopy investigations and theoretical calculations carried out on methanol and water adsorption on both anatase and rutile surfaces indicate that methanol and water adsorb competitively at the surface $\mathrm{Ti}^{3+}$ sites of $\mathrm{TiO}_{2}$, both molecularly and dissociatively, with methoxy and hydroxyl groups formation on both anatase and rutile. ${ }^{31-35}$ In gas-phase reactions, methanol surface photo-oxidation is expected to proceed through $\mathrm{C}-\mathrm{H}$ bond breaking and $\mathrm{H}$-transfer to neighbour bridged oxygen atoms ( $\mathrm{Ti}-$ $\mathrm{O}-\mathrm{Ti}$ ) or surface-bound hydroxyl groups (Ti-OH). The three $\mathrm{TiO}_{2}$ polymorphs are characterised by slightly different $\mathrm{Ti}-\mathrm{Ti}$ surface distances and thus different activation energies are expected for the surface reaction transition states on the three crystalline phases, affecting their photoactivity.

The specific surface area of the photocatalyst powders is also a key factor governing their photocatalytic performance. Indeed, sample R1-C (139 $\left.\mathrm{m}^{2} \mathrm{~g}^{-1}\right)$ was much more active than sample R2-C (2.2 $\left.\mathrm{m}^{2} \mathrm{~g}^{-1}\right)$. However, sample R $\left(25 \mathrm{~m}^{2} \mathrm{~g}^{-1}\right)$, also mainly consisting of rutile, was found to be more active than sample R1-C, despite of the lower surface area. Such behaviour might be related to the presence of $12 \mathrm{wt} \%$ brookite and also to the narrower band gap, which allowed sample $\mathrm{R}$ to absorb a larger portion of the incident photons (Fig. 2). Indeed, as shown in Fig. $6,1 \mathrm{wt} \% \mathrm{Pt} / \mathrm{R}$ was the only photocatalyst active under visible light $(\lambda>400 \mathrm{~nm})$, whereas no hydrogen evolution was detected under such conditions with all the other photocatalysts, including $1 \mathrm{wt} \% \mathrm{Pt} / \mathrm{R} 1-\mathrm{C}$, in full agreement with their UV-Vis absorption spectra in relation to the cut off properties of the $400 \mathrm{~nm}$ filter (Fig. 2). Furthermore, under visible light irradiation of $1 \mathrm{wt} \%$ $\mathrm{Pt} / \mathrm{R}$, a stoichiometric $\mathrm{H}_{2} / \mathrm{CO}_{2}$ evolution was obtained, without any $\mathrm{CO}$ production. On the other hand, Fig. 6 also shows that all investigated photocatalysts maintained a residual photo-activity when a $385 \mathrm{~nm}$ cut-off filter was employed. However, also in this

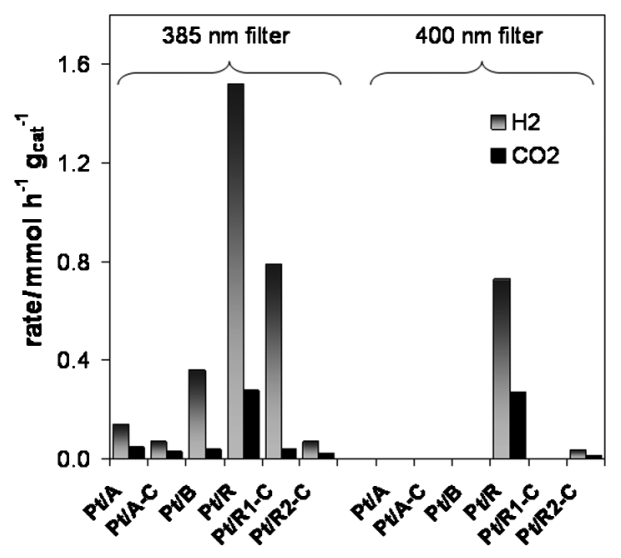

Fig. 6 Comparison of the rates of $\mathrm{H}_{2}$ and $\mathrm{CO}_{2}$ production on $1 \mathrm{wt} \%$ Pt-deposited $\mathrm{TiO}_{2}$ samples under irradiation in the $385<\lambda<450 \mathrm{~nm}$ range ( $385 \mathrm{~nm}$ filter) and in the $400<\lambda<450 \mathrm{~nm}$ range ( $400 \mathrm{~nm}$ filter). case $1 \mathrm{wt} \% \mathrm{Pt} / \mathrm{R}$ was the most active photocatalyst and no $\mathrm{CO}$ evolution occurred under such conditions.

\section{Conclusions}

Pure brookite in powder form, modified by deposition of $\mathrm{Pt}$ nanoparticles, proved to be a very good photocatalyst for hydrogen production from methanol-water vapours under UV-Vis irradiation, also in consideration of its high selectivity to $\mathrm{CO}_{2}$ formation and low $\mathrm{CO}$ production. Home-made photocatalyst $\mathrm{R}$, mainly consisting of rutile and also containing a brookite fraction, maintained a good photoactivity also under visible light irradiation, thanks to its ability to absorb longer wavelength light.

\section{Notes and references}

1 A. Fujishima, X. Zhang and D. A. Tryk, $\mathrm{TiO}_{2}$ photocatalysis and related surface phenomena, Surf. Sci. Rep., 2008, 63, 515.

2 X. Bokhimi, A. Morales, M. Aguilar, J. A. Toledo-Antonio and F. Pedraza, Local order in titania polymorphs, Int. J. Hydrogen Energy, 2001, 26, 1279.

3 H. Zhang and J. F. Banfield, Understanding polymorphic phase transformation behavior during growth of nanocrystalline aggregates: insights from $\mathrm{TiO}_{2}$, J. Phys. Chem. B, 2000, 104, 3481 .

4 C. A. Grimes, Synthesis and application of highly ordered arrays of $\mathrm{TiO}_{2}$ nanotubes, J. Mater. Chem., 2007, 17, 1451.

5 A. G. Kontos, A. Katsanaki, T. Maggos, V. Likodimos, A. Ghicov, D. Kim, J. Kunze, C. Vasilakos, P. Schmuki and P. Falaras, Photocatalytic degradation of gas pollutants on self-assembled titania nanotubes, Chem. Phys. Lett., 2010, 490, 58.

6 H. Kominami, J.-I. Kato, S.-Y. Murakami, Y. Ishii, M. Kohno, K.I. Yabutani, T. Yamamoto, Y. Kera, M. Inoe, T. Inui and B. Ohtani, Solvothermal syntheses of semiconductor photocatalysts of ultra-high activities, Catal. Today, 2003, 84, 181.

7 K. Tomita, V. Petrykin, M. Kobayashi, M. Shiro, M. Yoshimura and M. Kakihana, A water-soluble titanium complex for the selective synthesis of nanocrystalline brookite, rutile, and anatase by a hydrothermal method, Angew. Chem., Int. Ed., 2006, 45, 2378.

8 N. Murakami, T. Kamai, T. Tsubota and T. Ohno, Novel hydrothermal preparation of pure brookite-type titanium(IV) oxide nanocrystal under strong acidic conditions, Catal. Commun., 2009, 10, 963.

9 J. H. Lee and Y. S. Yang, Synthesis of $\mathrm{TiO}_{2}$ nanoparticles with pure brookite at low temperature by hydrolysis of $\mathrm{TiCl}_{4}$ using $\mathrm{HNO}_{3}$ solution, J. Mater. Sci., 2006, 41, 557.

10 A. Pottier, C. Chanéac, E. Tronc, L. Mazerolles and J. P. Jolivet, Synthesis of brookite $\mathrm{TiO}_{2}$ nanoparticles by thermolysis of $\mathrm{TiCl}_{4}$ in strongly acidic aqueous media, J. Mater. Chem., 2001, 11, 1116.

11 A. Di Paola, G. Cufalo, M. Addamo, M. Bellardita, R. Campostrini, M. Ischia, R. Ceccato and L. Palmisano, Photocatalytic activity of nanocrystalline $\mathrm{TiO}_{2}$ (brookite, rutile and brookite-based) powders prepared by thermohydrolysis of $\mathrm{TiCl}_{4}$ in aqueous chloride solutions, Colloids Surf., A, 2008, 317, 366.

12 S. Bakardjieva, V. Stengl, L. Szatmary, J. Subrt, J. Lukac, N. Murafa, D. Niznansky, K. Cizek, J. Jrkovsky and N. Petrova, Transformation of brookite-type $\mathrm{TiO}_{2}$ nanocrystals to rutile: correlation between microstructure and photoactivity, J. Mater. Chem., 2006, 16, 1709.

13 A. Sclafani, L. Palmisano and M. Schiavello, Influence of the preparation methods of titanium dioxide on the photocatalytic degradation of phenol in aqueous dispersion, J. Phys. Chem., 1990, 94, 829.

14 A. Di Paola, M. Addamo, M. Bellardita, E. Cazzanelli and L. Palmisano, Preparation of photocatalytic brookite thin films, Thin Solid Films, 2007, 515, 3527.

15 M. Addamo, M. Bellardita, A. Di Paola and L. Palmisano, Preparation and photoactivity of nanostructured anatase, rutile and brookite $\mathrm{TiO}_{2}$ thin films, Chem. Commun., 2006, 4943.

16 M. Addamo, V. Augugliaro, M. Bellardita, A. Di Paola, V. Loddo, G. Palmisano, L. Palmisano and S. Yurdakal, Environmentally friendly photocatalytic oxidation of aromatic alcohol to aldehyde in aqueous suspension of brookite $\mathrm{TiO}_{2}$, Catal. Lett., 2008, 126, 58 . 
17 H. Pan, X. Qiu, I. N. Ivanov, H. M. Meyer, W. Wanga, W. Zhu, M. P. Paranthaman, Z. Zhang, G. Eres and B. Gu, Fabrication and characterization of brookite-rich, visible light-active $\mathrm{TiO}_{2}$ films for water splitting, Appl. Catal., B, 2009, 93, 90.

18 T. A. Kandiel, A. Feldhoff, L. Robben, R. Dillert and D. W. Bahnemann, Tailored titanium dioxide nanomaterials: anatase nanoparticles and brookite nanorods as highly active photocatalysts, Chem. Mater., 2010, 22, 2050.

19 H. Kominami, Y. Ishii, M. Kohno, S. Konishi, Y. Kera and B. Ohtani, Nanocrystalline brookite-type titanium(IV) oxide photocatalysts prepared by a solvothermal method: correlation between their physical properties and photocatalytic activities, Catal. Lett., 2003, 91, 41.

20 B. I. Lee, S. Kaewgun, W. Kim, W. Choi, J. S. Lee and E. Kim, Visible light photocatalytic properties of polymorphic brookite titania, J. Renewable Sustainable Energy, 2009, 1, 023101.

21 A. Patsoura, D. I. Kondarides and X. E. Verykios, Photocatalytic degradation of organic pollutants with simultaneous production of hydrogen, Catal. Today, 2007, 124, 94.

22 N. Strataki, V. Bekiari, D. I. Kondarides and P. Lianos, Hydrogen production by photocatalytic alcohol reforming employing highly efficient nanocrystalline titania films, Appl. Catal., B, 2007, 77, 184.

23 G. L. Chiarello, E. Selli and L. Forni, Photocatalytic hydrogen production over flame spray pyrolysis-synthesised $\mathrm{TiO}_{2}$ and $\mathrm{Au} / \mathrm{TiO}_{2}$, Appl. Catal., B, 2008, 84, 332.

24 G. L. Chiarello, M. H. Aguirre and E. Selli, Hydrogen production by photocatalytic steam reforming of methanol on noble metal-modified $\mathrm{TiO}_{2}$, J. Catal., 2010, 273, 182.

25 G. L. Chiarello, L. Forni and E. Selli, Photocatalytic hydrogen production by liquid- and gas-phase reforming of $\mathrm{CH}_{3} \mathrm{OH}$ over flamemade $\mathrm{TiO}_{2}$ and $\mathrm{Au} / \mathrm{TiO}_{2}$, Catal. Today, 2009, 144, 69.
26 A. Di Paola, M. Bellardita, R. Ceccato, L. Palmisano and F. Parrino, Highly active photocatalytic $\mathrm{TiO}_{2}$ powders obtained by thermohydrolysis of $\mathrm{TiCl}_{4}$ in water, J. Phys. Chem. C, 2009, 113, 15166.

$27 \mathrm{H}$. M. Rietveld, A profile refinement method for nuclear and magnetic structures, J. Appl. Crystallogr., 1969, 2, 65.

28 A. Altomare, M. C. Burla, C. Giacovazzo, A. Guagliardi, A. G. G. Moliterni, G. Polidori and R. Rizzi, Quanto: a Rietveld program for quantitative phase analysis of polycrystalline mixtures, J. Appl. Crystallogr., 2001, 34, 392.

29 C. G. Hatchard and C. A. Parker, A new sensitive chemical actinometer. II. Potassium ferrioxalate as a standard chemical actinometer., Proc. R. Soc. London, Ser. A, 1956, 235, 518.

30 C. Kormann, D. W. Bahnemann and M. R. Hoffmann, Preparation and characterization of quantum-size titanium dioxide, J. Phys. Chem., 1988, 92, 5196.

31 A. Yamakata, T. Ishibashi and H. Onishi, Electron- and hole-capture reactions on $\mathrm{Pt} / \mathrm{TiO}_{2}$ photocatalyst exposed to methanol vapor studied with time-resolved infrared absorption spectroscopy, J. Phys. Chem. B, 2002, 106, 9122.

32 C. Wang, H. Groenzin and M. J. Shultz, Surface characterization of nanoscale $\mathrm{TiO}_{2}$ film by sum frequency generation using methanol as a molecular probe, J. Phys. Chem. B, 2004, 108, 265.

33 T. Chen, Z. Feng, G. Wu, J. Shi, G. Ma, P. Ying and C. Li, Mechanistic studies of photocatalytic reaction of methanol for hydrogen production on $\mathrm{Pt} / \mathrm{TiO}_{2}$ by in situ Fourier transform IR and time-resolved IR spectroscopy, J. Phys. Chem. C, 2007, 111, 8005.

34 A. Tilocca and A. Selloni, Methanol adsorption and reactivity on clean and hydroxylated anatase(101) surfaces, J. Phys. Chem. B, 2004, 108, 19314.

35 Y. Han, C. Liu and Q. Ge, Effect of Pt clusters on methanol adsorption and dissociation over perfect and defective anatase $\mathrm{TiO}_{2}(101)$ surface, J. Phys. Chem. C, 2009, 113, 20674. 